\title{
ACTD: BRIDGE BETWEEN REGULATORY REQUIREMENTS OF DEVELOPED AND DEVELOPING COUNTRIES
}

\author{
Available online at www.ijdra.com \\ REVIEW ARTICLE \\ ${ }^{1}$ Jain Achin*, ${ }^{1}$ Venkatesh M.P., ${ }^{1}$ Kumar Pramod T.M. \\ ${ }^{1}$ J.S.S. College of Pharmacy, S.S. Nagar, Bannimantap, Mysore, India. \\ *Corresponding Author's E-mail: achinjain16@yahoo.co.in
}

\begin{abstract}
:
Regulatory Dossier contains data which when submitted to the regulatory authority, provides for the review and ultimate approval of a drug product. Once approved, an applicant may manufacture and market the drug to provide a safe, effective and low cost which benefits the society. Filing requirements in developed countries differ from developing countries which makes the approval process tedious and time consuming for the later. To make this process smooth, ASEAN CTD (ACTD) was developed by Association of South East Asian Nations (ASEAN) nations. As format of ACTD resembles the format of Common Technical Document (CTD) with some differences, hence it can be used as a step. Also if both guidelines can be harmonized then differences and variation between both the guidelines can be minimized. This article focuses on the similarities and differences in between CTD \& ACTD and highlights how ACTD can be a initiating step for developing countries to meet pharmaceutical regulations of developed countries.
\end{abstract}

Key words: ACTD, ASEAN, CTD, eCTD, ICH.

\section{Introduction:}

ACTD (ASEAN Common technical document) is the submission format for dossier which is accepted in most of the ASEAN (Association of South-East Asian Nations) which are mostly developing nations. ACTD have been adopted at the $7^{\text {th }}$ PPWG (Pharmaceuticals Product Working Group) Meeting in 2003. After a trial period that started in 2003 it was agreed that ACTD shall be implemented by all ASEAN countries originally by $31 \mathrm{Dec} 2006$. The due date for implementation was postponed to 31 Dec 2008 in order to allow member countries to transpose ACTD requirements into their local regulations.

ACTD was prepared based on CTD (Common technical document) as per ICH-M4 (International Conference on Harmonization). The main aim of ACTD was to regulate the pharmaceutical regulations of the ASEAN member countries in order to complement and facilitate the objective of AFTA (ASEAN Free Trade Area), particularly, the elimination of technical barriers to trade posed by regulations, without compromising the quality, efficacy and safety of drugs. The development of ACTD can also help the developing nation to register their product in developed countries like US and Europe hassle-free. ACTD format data requirement is nearly similar to those of CTD which is accepted in some of developed countries also.

The CTD was developed by the ICH working group with representatives from regulatory bodies in Europe, Japan and the United States. The CTD is a set of specifications for the submission of regulatory data in the application for the right to market pharmaceuticals. These applications include New Drug Applications (NDA), Marketing Authorization Applications (MAA), as well as Investigational New Drug Applications (IND) or clinical Trial Applications (CTA). The CTD is not a "Global Dossier". The eCTD (electronic Common Technical Document) is defined as an interface for industry to agency transfer of regulatory information while at the same time taking into consideration the facilitation of the creation, review, life cycle management and archiving of the electronic submission. 


\section{Need and development of regulations for Registration of Medicinal Products}

The modern medicines regulation started only after breakthrough progress in the $19^{\text {th }}$ century life sciences, especially in chemistry, physiology and pharmacology, which laid a solid foundation for the modern drug research.

In 1937, over 100 people in the United States died of diethylene glycol poisoning following the use of a sulfanilamide elixir (1), which used the chemical as a solvent without any safety testing. This facilitated introduction of The Federal Food, Drug and Cosmetic Act with the pre-market notification requirement for new drugs in 1938. (2)

The second catastrophe that influenced the development of medicines regulation far more than any event in history was the thalidomide disaster. Thalidomide was a sedative and hypnotic that first went on sale in Western Germany in 1956. Between 1958 and 1960 it was introduced in 46 different countries worldwide resulting in an estimated 10,000 babies being born with Phocomelia and other deformities. (3) The role of this disaster in shaping the medicines regulatory systems is not hard to underestimate. As a result the whole regulatory system was reshaped in the UK where a Committee on the Safety of Drugs (CSD) was started in 1963 followed by a voluntary adverse drug reaction reporting system (Yellow Card Scheme) in 1964. (4)

In the United States, The Drug Amendments Act of 1962 (2) was passed by Congress requiring the food and drug administration (FDA) to approve all new drug applications (NDA) and, for the first time, demanded that a new drug should be proven to be effective and safe. Of equal importance, the FDA was also given the authority to require compliance with current Good Manufacturing Practices (cGMP), to officially register drug establishments and implement other requirements. The European Economic Community (EEC) Directive 65/65/EEC on the approximation of provisions laid down by law, regulation and administrative action relating to medicinal products was also induced by the thalidomide disaster. (5)
In 1975, two Council Directives were introduced, the first on approximation of the laws of Member States relating to analytical, pharmacotoxicological and clinical standards and protocols in respect of the testing of proprietary medicinal products (75/318/EEC), and the second on the approximation of provisions laid down by law, regulation and administrative action relating to medicinal products (75/319/EEC). (6)The latter established an 'old' Committee on Proprietary Medicinal Products (CPMP) as an advisory committee to the expert committee (EC) and introduced the multistate procedure known now as the mutual recognition procedure. Directive 87/22/EEC introduced the concentration procedure which is now known as the centralized procedure. These directives, and following council regulation, were the landmarks for starting harmonization inside the European Union with the final longstanding aim of creating a 'common market' for medicines. The Council Regulation EEC/2309/93 established the European Medicines Evaluation Agency (EMEA) in 1993 (7) and re-established the CPMP as a 'new' CPMP to formulate the opinion of the Agency on questions relating to the submission of applications and granting marketing authorizations in accordance with the centralized procedure.

The developing countries have now emerged with guidelines for the drug marketing approval but the pharmaceutical industries are still facing many problems to get their product approval in developed market. The main concern is that all countries have different regulations which are country specific so if a product is registered in one country then to get it registered in another country they have to do all documentation work again. All this work was done on papers so it give rise to a bulk of volumes of compiled data which was difficult task to maintain and to store. Moreover from that bulk of volumes to trace any data for a particular country was a difficult task. Data for each country was arranged usually on the basis of table of content.

Due to the above concerns, there was the need of some harmonized guideline for product registration. The need for wider harmonization 
was initiated after preliminary contacts between officials from Japan, EU and US discussed during the International Conference of Drug Regulatory Authorities (ICDRA) at Paris in 1989 which led to the establishment in 1990 of the International Conference on Harmonization of Technical Requirements for the Registration of Pharmaceuticals for Human Use (ICH), a collaborative initiative between the EU, Japan and the United States with observers from WHO, European Free Trade Association (EFTA) and Canada. (4) ICH harmonization focuses primarily on technical requirements for new, innovative medicines. Pharmaceutical regulatory harmonization facilitates the availability of safe, effective and good quality pharmaceuticals. This ICH committee gives rise to the Common Technical Document (CTD) as a set of specification for application dossier, for the registration of Medicines and designed to be used across Europe, Japan and the United States.

\section{Development of ACTD}

In-line with the development of CTD by ICH, efforts toward ASEAN harmonization was also initiated through the ASEAN Consultative Committee for Standards and Quality (ACCSQ), which was formed by the ASEAN Economic Ministers in 1992 to facilitate and complement the objectives of the AFTA and to eventually implement the mutual recognition arrangements (MRAs).

Four areas in pharmaceuticals have been identified for harmonization-quality, efficacy, safety, and administration data.

Key documents resulted from the work of PPWG include:

- ASEAN Common Technical Requirements (ACTR) for pharmaceutical product registration (for human use)

- ASEAN Common Technical Dossier (ACTD) for pharmaceutical product registration (for human use)

- ASEAN Guidelines on the following areas: Analytical Validation, Bioavailability and Bioequivalence studies, Process Validation, Stability study.

The new harmonized system has been put to use, starting 2004, in parallel to existing systems in member countries. There are differential requirements based on the members' readiness in the implementation of the common requirements and dossiers. For example, product applications to be registered in Laos based on ACTD format are allowed to use bioequivalence studies conducted in a foreign country while in Thailand bioequivalence study on local population is mandatory.

The key feature in the ASEAN common technical requirements and dossiers for pharmaceutical registration is the emphasis on the registration of generic drugs. This is due to the fact that the majority of local pharmaceutical industry in this region is a generic industry. Therefore, products registered in ASEAN member countries are primarily generic products. For new chemical and biological drugs, the ASEAN safety standards are basically in line with ICH requirements; efficacy evidence required is also in line with that of ICH. The sequences of data entry in the application form between the two differ, however.

The ACTD gives information on the format and structure of the dossier that shall be commonly used for applications in the ASEAN region. The ACTD should serve as a locator for documentation that has been compiled for a marketing authorization application. It does not give any recommendations on the actual content of the dossier. The advantage of the ACTD is that one dossier can be used for the whole region rather than generating different registration dossiers. ACTD should therefore significantly reduce time and resources needed to compile applications. The harmonized format should also facilitate the regulatory review. Thailand was the lead country to develop the overall ACTD organization with input from the different working groups for the administrative part, quality, non-clinical and clinical part. (8)

The Common Technical Document is organized into four parts as follows:

Part I Table of Contents, Administrative Data and Product Information

Part II Quality Document 
Part III Nonclinical Document

Part IV Clinical Document

\section{$\underline{\text { ACTD and its organization }}$}

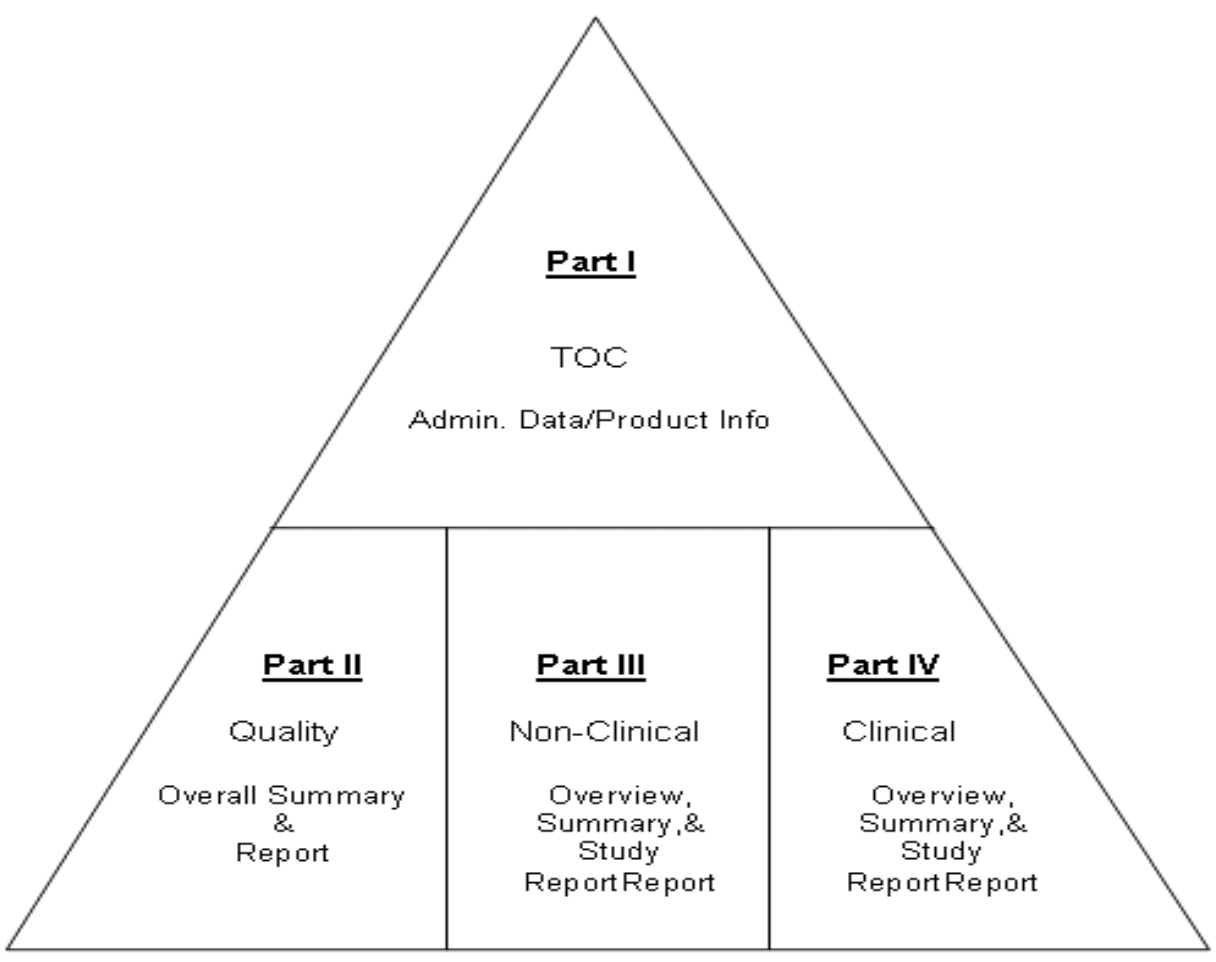

ASEAN CTD

Figure 1: Modular structure of ACTD

\section{CTD and its Organization}

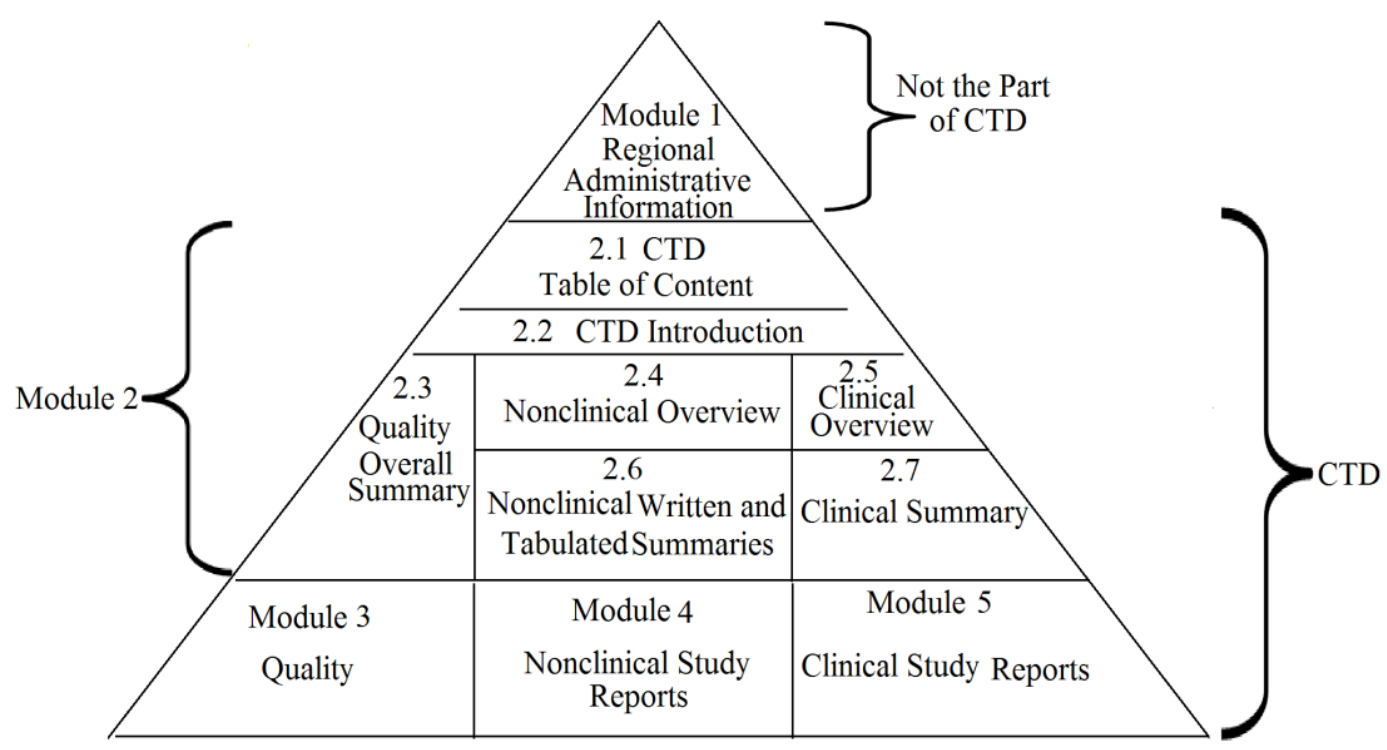

Figure 2: Modular Structure of CTD (9) 
A common format for the technical documentation will significantly reduce the time and resources used to compile applications for registration of human pharmaceuticals and will ease the preparation of electronic submissions. Regulatory reviews and communication with the applicant will be facilitated by a standard document of common elements. Through the ICH process, considerable harmonization has been achieved among the three regions (Japan, Europe, and the United States) in the organization of a submission for the registration of pharmaceuticals for human use.

According to the CTD format (Figure 1), each submission of a marketing application is a collection of documents, grouped into 5 modules:

Module 1:- Administrative and prescribing information (region specific)

Module 2:- Summaries and overview

Module 3:- Information on product quality

Module 4:- Nonclinical study reports

Module 5:- Clinical study reports

Even though a harmonized guideline exists, the volume of data required to submit is huge which consumes a lot of paper and is not reviewer friendly. This process becomes time consuming and tedious. Also navigation throughout the document was a difficult task. Storage and maintenance was a bigger challenge for regulatory agency as well as pharmaceutical company. This led to the development of electronic submission known as eCTD.

\section{eCTD}

ICH-eCTD is an internationally driven standard, designed to reduce cost in the administration, assessment and archiving of applications for marketing authorization of medicinal products for human use, to reduce the use of paper and streamline the assessment process making the system more efficient. (10)

eCTD is necessary for the following reasons

- Improve the submission and review process

- Increase accuracy of the submission

- Decrease total costs
This specification has been developed by the ICH M2 Expert Working group and maintained by the eCTD Implementation Working group in accordance with the ICH Process.

\section{Differences in CTD and ACTD format}

Guidance on the structure and format of ACTD is given in the document called ACTD organisation. This document is similar to the ICH Guideline M4 (R3) Organisation of CTD, but there are differences in numbering, granularity and naming of sections.

- The ACTD consists of Parts I to IV which have subsections A to F. In comparison the ICH-CTD has five Modules with subsections that are numbered.

- The administrative data of Part I is part of ACTD, whereas Module 1 of the ICH-CTD is purely country specific. Any additional data not contained in the main sections of the ACTD should be included as addenda to the relevant section.

- The summaries of the quality, non-clinical and clinical are located at the beginning of Part II (Section B), Part III (Section C) \& Part IV (Section C) respectively of the ACTD. The ICH-CTD dedicates these summaries a separate Module 2. As the ACTD does not have such summary part it consists only of four Parts and not five.

- The rationale for ASEAN member countries not to adapt ICH-CTD but to develop their own ACTD was that the majority of pharmaceuticals registered in ASEAN are Generics, and health authorities mainly review the quality part. Consolidating the quality data under a single part facilitates review, rather than having this information separated over two Modules like in the ICHCTD (M2 contains Quality Overall Summary and M3 Body of data).

- The ACTD pagination is more flexible than the ICH-CTD. The preamble of the ACTD organizations just mentions the ACTD index and that the dossier should be numbered with the first page of each part designated as page 1. No further granularity, segregation or pagination is defined. Compared to the ASEAN the requirements of the $\mathrm{ICH}$-dossier are more complex. 


\section{Harmonized format for CTD and ACTD}

\begin{tabular}{|c|c|c|c|}
\hline \multicolumn{2}{|c|}{ Section 1: Regional Administrative Information } & \multirow{2}{*}{$\frac{\text { CTD }}{\checkmark}$} & \multirow{2}{*}{$\frac{\text { ACTD }}{\checkmark}$} \\
\hline 1. & Guidance on the administrative data and product information & & \\
\hline 1.1 & Forms & $\sqrt{ }$ & $\sqrt{ }$ \\
\hline 1.2 & Cover Letter & $\checkmark$ & $x$ \\
\hline 1.3 & Administrative Information & $\checkmark$ & $x$ \\
\hline 1.3 .1 & Contact / Sponsor Information & $\checkmark$ & $x$ \\
\hline 1.3 .2 & Field Copy Certification & $\checkmark$ & $x$ \\
\hline 1.3 .3 & Debarment Certification & $\checkmark$ & $x$ \\
\hline 1.3 .4 & $\begin{array}{l}\text { Certification: Financial Interests and Arrangements of Clinical } \\
\text { Investigators (FDA Form 3454) }\end{array}$ & $\checkmark$ & $x$ \\
\hline 1.3 .5 & Patent \& Exclusivity & $\checkmark$ & $x$ \\
\hline 1.4 & References & $\checkmark$ & $x$ \\
\hline 1.4 .1 & Letters of Authorization & $\sqrt{ }$ & $\checkmark$ \\
\hline 1.4 .2 & Statement of Right of Reference & $\checkmark$ & $x$ \\
\hline 1.4 .3 & List of Authorized Persons to Incorporate by Reference & $\checkmark$ & $x$ \\
\hline 1.4 .4 & $\begin{array}{l}\text { Cross Reference to Other Applications \& Previously Submitted } \\
\text { Information }\end{array}$ & $\checkmark$ & $x$ \\
\hline 1.5 & Application Status & $\checkmark$ & $x$ \\
\hline 1.6 & Meetings & $\checkmark$ & $x$ \\
\hline 1.6 .1 & Meeting Request & $\checkmark$ & $x$ \\
\hline 1.6 .2 & Meeting Background Materials & $\checkmark$ & $x$ \\
\hline 1.6 .3 & Correspondence Regarding Meetings & $\checkmark$ & $x$ \\
\hline 1.7 & Fast Track & $\checkmark$ & $x$ \\
\hline 1.8 & Special Protocol Assessment (SAP) Request & $\checkmark$ & $x$ \\
\hline 1.9 & Pediatric Administrative Information & $\checkmark$ & $x$ \\
\hline 1.9 .1 & Request for Waiver & $\checkmark$ & $x$ \\
\hline 1.9 .2 & Request for Deferral & $\checkmark$ & $x$ \\
\hline 1.9 .3 & Request for Pediatric Exclusivity Determination & $\checkmark$ & $x$ \\
\hline 1.9 .4 & Proposed Pediatric Study Request \& Amendments & $\checkmark$ & $x$ \\
\hline 1.9 .5 & Proposal for Written Agreement & $\checkmark$ & $x$ \\
\hline 1.9 .6 & $\begin{array}{l}\text { Other Correspondence Regarding Pediatric Exclusivity or Study } \\
\text { Plans }\end{array}$ & $\checkmark$ & $x$ \\
\hline 1.10 & Dispute Resolutions & $\checkmark$ & $x$ \\
\hline 1.10 .1 & Request for Dispute Resolution & $\checkmark$ & $x$ \\
\hline 1.10 .2 & Correspondence Relating to Dispute Resolution & $\checkmark$ & $x$ \\
\hline 1.11 & Information Amendment (not covered under Modules 2-5) & $\checkmark$ & $x$ \\
\hline 1.11 .1 & Quality & $\checkmark$ & $x$ \\
\hline 1.11 .2 & Safety & $\checkmark$ & $x$ \\
\hline 1.11 .3 & Efficacy & $\checkmark$ & $x$ \\
\hline 1.12 & Other Correspondence & $\checkmark$ & $x$ \\
\hline 1.12 .1 & Pre-IND Correspondence & $\checkmark$ & $x$ \\
\hline 1.12 .2 & Request to Charge & $\checkmark$ & $x$ \\
\hline 1.12 .3 & Notification of Charging Under Treatment IND & $\checkmark$ & $x$ \\
\hline
\end{tabular}




\begin{tabular}{|c|c|c|c|}
\hline 1.12 .4 & Request for Comments and Advice on an IND & $\checkmark$ & $x$ \\
\hline 1.12 .5 & Request for Waiver & $\checkmark$ & $x$ \\
\hline 1.12 .6 & Exemption from Informed Consent for Emergency Research & $\checkmark$ & $x$ \\
\hline 1.12 .7 & Public Disclosure Statement for Emergency Care Research & $\checkmark$ & $x$ \\
\hline 1.12 .8 & Correspondence Regarding Emergency Care Research & $\checkmark$ & $x$ \\
\hline 1.12 .9 & Notification of Discontinuation of Clinical Trial & $\checkmark$ & $x$ \\
\hline 1.12 .10 & Generic Drug Enforcement Act (GDEA) Statement & $\checkmark$ & $x$ \\
\hline 1.12 .11 & Basis for Submission Statement & $\checkmark$ & $x$ \\
\hline 1.12 .12 & Comparison of Generic Drug and Reference Listed Drug (RLD) & $\checkmark$ & $x$ \\
\hline 1.12 .13 & Request for Waiver of in vivo Studies & $\checkmark$ & $x$ \\
\hline 1.12 .14 & Environmental Impact Analysis Statement & $\checkmark$ & $x$ \\
\hline 1.12 .15 & Request for Waiver of in vivo Bioavailability Studies & $\checkmark$ & $x$ \\
\hline 1.12 .16 & Field Alert Reports & $\checkmark$ & $x$ \\
\hline 1.13. & Annual Reports & $\checkmark$ & $x$ \\
\hline 1.13 .1 & Summary for Non-Clinical Studies & $\checkmark$ & $x$ \\
\hline 1.13 .2 & Summary of Clinical Pharmacology Studies & $\checkmark$ & $x$ \\
\hline 1.13 .3 & Summary of Safety Information & $\checkmark$ & $x$ \\
\hline 1.13 .4 & Summary of Labeling Changes & $\checkmark$ & $x$ \\
\hline 1.13 .5 & Summary of Manufacturing Changes & $\checkmark$ & $x$ \\
\hline 1.13 .6 & Summary of Microbiological Changes & $\checkmark$ & $x$ \\
\hline 1.13 .7 & Summary of Other Significant New Information & $\checkmark$ & $x$ \\
\hline 1.13 .8 & Individual Study Information & $\checkmark$ & $x$ \\
\hline 1.13 .9 & General Investigational Plan & $\checkmark$ & $x$ \\
\hline 1.13 .10 & Foreign Marketing History & $\checkmark$ & $x$ \\
\hline 1.13 .11 & Distribution Data & $\checkmark$ & $x$ \\
\hline 1.13 .12 & Status of Post-Marketing Commitments & $\checkmark$ & $x$ \\
\hline 1.13 .13 & Status of Other Post-Marketing Studies & $\checkmark$ & $x$ \\
\hline 1.13 .14 & Log of Outstanding Regulatory Business & $\checkmark$ & $x$ \\
\hline 1.14 & Labeling & $\checkmark$ & $\sqrt{ }$ \\
\hline 1.14 .1 & Draft Labeling & $\checkmark$ & $x$ \\
\hline 1.14 .2 & Final Labeling & $\checkmark$ & $x$ \\
\hline 1.14 .3 & Listed Drug Labeling & $\checkmark$ & $x$ \\
\hline 1.14 .4 & Investigational Drug Labeling & $\checkmark$ & $x$ \\
\hline 1.15 & Promotional Material & $\checkmark$ & $x$ \\
\hline 1.16 & Risk Management Plans & $\checkmark$ & $x$ \\
\hline 1.17 & Certifications & $x$ & $\sqrt{ }$ \\
\hline 1.17 .1 & For contract manufacturing & $x$ & $\sqrt{ }$ \\
\hline 1.17 .2 & For manufacturing "under-license" ( country specific ): & $x$ & $\bar{\checkmark}$ \\
\hline 1.17 .3 & For imported products: & $x$ & $\checkmark$ \\
\hline 1.18 & Product Information & $x$ & $\checkmark$ \\
\hline 1.18 .1 & Package Insert & $x$ & $\checkmark$ \\
\hline 1.18 .2 & Summary of Product Characteristics (Product Data Sheet) & $x$ & $\checkmark$ \\
\hline 1.18 .3 & Patient Information Leaflet (PIL) & $x$ & $\sqrt{ }$ \\
\hline
\end{tabular}




\begin{tabular}{|c|c|c|c|}
\hline \multicolumn{2}{|c|}{ Section 2 Common Technical Document Summaries } & \multirow{2}{*}{$\begin{array}{l}\text { CTD } \\
\checkmark\end{array}$} & \multirow{2}{*}{$\frac{\text { ACTD }}{\checkmark}$} \\
\hline 2.1 & Comprehensive Table of Contents for Module 2 & & \\
\hline 2.2 & Introduction & $\checkmark$ & $\checkmark$ \\
\hline 2.3 & Quality Summary & $\checkmark$ & $\sqrt{ }$ \\
\hline 2.3.S & Drug Substance & $\checkmark$ & $\checkmark$ \\
\hline 2.3.S.1 & General Information & $\checkmark$ & $\checkmark$ \\
\hline 2.3.S.2 & Manufacture & $\checkmark$ & $\sqrt{ }$ \\
\hline 2.3.S.3 & Characterization & $\checkmark$ & $\checkmark$ \\
\hline 2.3.S.4 & Control of Drug Substance & $\checkmark$ & $\checkmark$ \\
\hline 2.3.S.5 & Reference Standards or Materials & $\checkmark$ & $\checkmark$ \\
\hline 2.3.S.6 & Container / Closure System & $\checkmark$ & $\sqrt{ }$ \\
\hline 2.3.S.7 & Stability & $\checkmark$ & $\sqrt{ }$ \\
\hline 2.3.P & Drug Product & $\sqrt{ }$ & $\checkmark$ \\
\hline 2.3.P.1 & Description and Composition of the Drug Product & $\checkmark$ & $\checkmark$ \\
\hline 2.3.P.2 & Pharmaceutical Development & $\checkmark$ & $\checkmark$ \\
\hline 2.3.P.3 & Manufacture & $\checkmark$ & $\sqrt{ }$ \\
\hline 2.3.P.4 & Control of Excipients & $\checkmark$ & $\checkmark$ \\
\hline 2.3.P.5 & Control of Drug Product & $\checkmark$ & $\checkmark$ \\
\hline 2.3.P.6 & Reference Standards or Materials & $\checkmark$ & $\checkmark$ \\
\hline 2.3.P.7 & Container / Closure System & $\checkmark$ & $\checkmark$ \\
\hline 2.3.P.8 & Stability & $\checkmark$ & $\checkmark$ \\
\hline 2.3.P.9 & Product interchangeability & $x$ & $\checkmark$ \\
\hline $2.3 . \mathrm{R}$ & Regional Information & $\checkmark$ & $x$ \\
\hline 2.4 & Non-clinical Overview & $\checkmark$ & $\checkmark$ \\
\hline 2.4 .1 & Overview of the Non-clinical Testing Strategy & $\checkmark$ & $\checkmark$ \\
\hline 2.4 .2 & Pharmacology & $\checkmark$ & $\checkmark$ \\
\hline 2.4 .3 & Pharmacokinetics & $\sqrt{ }$ & $\sqrt{ }$ \\
\hline 2.4 .4 & Toxicology & $\checkmark$ & $\checkmark$ \\
\hline 2.4 .5 & Integrated Overview and Conclusions & $\checkmark$ & $\checkmark$ \\
\hline 2.4 .6 & List of Literature Citations & $\checkmark$ & $\sqrt{ }$ \\
\hline 2.5 & Clinical Overview & $\checkmark$ & $\checkmark$ \\
\hline 2.5 .1 & Product Development Rationale & $\checkmark$ & $\checkmark$ \\
\hline 2.5 .2 & Overview of Biopharmaceutics & $\checkmark$ & $\checkmark$ \\
\hline 2.5 .3 & Overview of Clinical Pharmacology & $\checkmark$ & $\checkmark$ \\
\hline 2.5 .4 & Overview of Efficacy & $\checkmark$ & $\sqrt{ }$ \\
\hline 2.5 .5 & Overview of Safety & $\checkmark$ & $\checkmark$ \\
\hline 2.5 .6 & Benefits and Risks Conclusions & $\checkmark$ & $\checkmark$ \\
\hline 2.5 .7 & References & $\checkmark$ & $\checkmark$ \\
\hline 2.6 & Non-clinical Written and Tabulated Summaries & $\checkmark$ & $\checkmark$ \\
\hline 2.6 .1 & Introduction & $\checkmark$ & $\checkmark$ \\
\hline 2.6 .2 & Pharmacology Written Summary & $\checkmark$ & $\checkmark$ \\
\hline 2.6 .3 & Pharmacology Tabulated Summary & $\checkmark$ & $\checkmark$ \\
\hline 2.6 .4 & Pharmacokinetics Written Summary & $\checkmark$ & $\checkmark$ \\
\hline 2.6 .5 & Pharmacokinetics Tabulated Summary & $\checkmark$ & $\checkmark$ \\
\hline
\end{tabular}




\begin{tabular}{|c|c|c|c|}
\hline 2.6 .6 & Toxicology Written Summary & $\checkmark$ & $\checkmark$ \\
\hline 2.6 .7 & Toxicology Tabulated Summary & $\checkmark$ & $\checkmark$ \\
\hline 2.7 & Clinical Summary & $\checkmark$ & $\checkmark$ \\
\hline 2.7 .1 & Summary of Biopharmaceutic and Associated Analytical Methods & $\checkmark$ & $\checkmark$ \\
\hline 2.7 .2 & Summary of Clinical Pharmacology Studies & $\checkmark$ & $\checkmark$ \\
\hline 2.7 .3 & Summary of Clinical Efficacy & $\sqrt{ }$ & $\sqrt{ }$ \\
\hline 2.7 .4 & Summary of Clinical Safety & $\sqrt{ }$ & $\sqrt{ }$ \\
\hline 2.7 .4 .1 & Exposure to the Drug & $\checkmark$ & $\checkmark$ \\
\hline 2.7 .4 .2 & Adverse Events & $\checkmark$ & $\checkmark$ \\
\hline 2.7 .4 .3 & Clinical Laboratory Evaluations & $\checkmark$ & $\checkmark$ \\
\hline 2.7 .4 .4 & Vital Signs, Physical Findings, Observations Related to Safety & $\checkmark$ & $\sqrt{ }$ \\
\hline 2.7 .4 .5 & Safety in Special Groups and Situations & $\checkmark$ & $\checkmark$ \\
\hline 2.7 .4 .6 & Post-Marketing Data & $\sqrt{ }$ & $\checkmark$ \\
\hline 2.7 .4 .7 & Appendix & $\checkmark$ & $x$ \\
\hline 2.7 .5 & References & $\checkmark$ & $\checkmark$ \\
\hline 2.7 .6 & Synopses of Individual Studies & $\sqrt{ }$ & $\sqrt{ }$ \\
\hline \multicolumn{2}{|c|}{ Section 3 Quality } & CTD & ACTD \\
\hline 3.1 & Comprehensive Table of Contents for Module 3 & $\checkmark$ & $\checkmark$ \\
\hline $3.2 . \mathrm{S}$ & Drug Substance & $\checkmark$ & $\checkmark$ \\
\hline $3.2 . \mathrm{S} .1$ & General Information & $\checkmark$ & $\checkmark$ \\
\hline 3.2.S.2 & Manufacture & $\checkmark$ & $\checkmark$ \\
\hline 3.2.S.3 & Characterization & $\checkmark$ & $\checkmark$ \\
\hline $3.2 . \mathrm{S} .4$ & Control of Drug Substance & $\checkmark$ & $\checkmark$ \\
\hline $3.2 . \mathrm{S} .5$ & Reference Standards or Materials & $\checkmark$ & $\checkmark$ \\
\hline 3.2.S.6 & Container / Closure Systems & $\checkmark$ & $\checkmark$ \\
\hline 3.2.S.7 & Stability & $\checkmark$ & $\checkmark$ \\
\hline 3.2.P & Drug Product & $\checkmark$ & $\checkmark$ \\
\hline 3.2.P.1 & Description and Composition of the Drug Product & $\checkmark$ & $\checkmark$ \\
\hline 3.2.P.2 & Pharmaceutical Development & $\checkmark$ & $\checkmark$ \\
\hline 3.2.P.3 & Manufacture & $\checkmark$ & $\checkmark$ \\
\hline 3.2.P.4 & Control of Excipients & $\checkmark$ & $\checkmark$ \\
\hline 3.2.P.5 & Control of Drug Product & $\checkmark$ & $\checkmark$ \\
\hline 3.2.P.6 & Reference Standards or Materials & $\checkmark$ & $\checkmark$ \\
\hline 3.2.P.7 & Container / Closure System & $\checkmark$ & $\checkmark$ \\
\hline 3.2.P.8 & Stability & $\checkmark$ & $\checkmark$ \\
\hline 3.2.P.9 & Product interchangeability & $x$ & $\checkmark$ \\
\hline 3.3 & Key Literature References & $\checkmark$ & $\checkmark$ \\
\hline \multicolumn{2}{|c|}{ Section 4 Non-Clinical Study Reports } & CTD & ACTD \\
\hline 4.1 & Comprehensive Table of Contents for Module 4 & $\checkmark$ & $\checkmark$ \\
\hline 4.2 & Study Reports & $\checkmark$ & $\checkmark$ \\
\hline 4.2 .1 & Pharmacology & $\checkmark$ & $\checkmark$ \\
\hline 4.2 .2 & Pharmacokinetics & $\checkmark$ & $\checkmark$ \\
\hline 4.2 .3 & Toxicology & $\checkmark$ & $\checkmark$ \\
\hline 4.2 .3 .1 & Single-Dose Toxicity & $\checkmark$ & $\checkmark$ \\
\hline
\end{tabular}




\begin{tabular}{|c|c|c|c|}
\hline 4.2 .3 .2 & Repeat-Dose Toxicity & $\checkmark$ & $\sqrt{ }$ \\
\hline 4.2.3.3 & Genotoxicity & $\checkmark$ & $\checkmark$ \\
\hline 4.2 .3 .4 & Carcinogenicity & $\checkmark$ & $\checkmark$ \\
\hline 4.2 .3 .5 & Reproductive and Development Toxicity & $\checkmark$ & $\checkmark$ \\
\hline 4.2 .3 .6 & Local Tolerance & $\checkmark$ & $\checkmark$ \\
\hline 4.2.3.7 & Other Toxicity Studies & $\checkmark$ & $\checkmark$ \\
\hline 4.2.3.7.1 & Antigenicity & $\checkmark$ & $\checkmark$ \\
\hline 4.2 .3 .7 .2 & Immunogenicity & $\checkmark$ & $\checkmark$ \\
\hline 4.2.3.7.3 & Mechanistic Studies & $\checkmark$ & $x$ \\
\hline 4.2 .3 .7 .4 & Dependence & $\checkmark$ & $\checkmark$ \\
\hline 4.2.3.7.5 & Metabolites & $\checkmark$ & $\checkmark$ \\
\hline 4.2 .3 .7 .6 & Impurities & $\checkmark$ & $\checkmark$ \\
\hline 4.2 .3 .7 .7 & Other & $\sqrt{ }$ & $\checkmark$ \\
\hline 4.3 & Literature References & $\checkmark$ & $\checkmark$ \\
\hline \multicolumn{2}{|c|}{ Section 5 Clinical Study Reports } & CTD & ACTD \\
\hline 5.1 & Comprehensive Table of Contents for Module 5 & $\checkmark$ & $\checkmark$ \\
\hline 5.2 & Tabular Listing of All Clinical Studies & $\checkmark$ & $\checkmark$ \\
\hline 5.3 & Clinical Study Reports & $\checkmark$ & $\checkmark$ \\
\hline 5.3 .1 & Reports of Biopharmaceutic Studies & $\checkmark$ & $\checkmark$ \\
\hline 5.3 .2 & Reports of Studies Pertinent to Human PK & $\checkmark$ & $\checkmark$ \\
\hline 5.3 .3 & Reports of Human PK Studies & $\checkmark$ & $\checkmark$ \\
\hline 5.3 .3 .1 & Healthy Subject PK and Tolerability & $\checkmark$ & $\checkmark$ \\
\hline 5.3.3.2 & Patient PK and Initial Tolerability & $\checkmark$ & $\checkmark$ \\
\hline 5.3.3.3 & Intrinsic Factor PK & $\checkmark$ & $x$ \\
\hline 5.3.3.4 & Extrinsic Factor PK & $\checkmark$ & $x$ \\
\hline 5.3.3.5 & Population PK & $\checkmark$ & $\checkmark$ \\
\hline 5.3 .4 & Reports of Human PD Studies & $\checkmark$ & $\checkmark$ \\
\hline 5.3 .5 & Reports of Efficacy and Safety Studies & $\checkmark$ & $\checkmark$ \\
\hline 5.3 .6 & Reports of Post-Marketing Experience & $\checkmark$ & $\checkmark$ \\
\hline 5.3 .7 & Case Report Forms (CRF)/Individual Patient Listings & $\checkmark$ & $\sqrt{ }$ \\
\hline 5.4 & Literature References & $\sqrt{ }$ & $\sqrt{ }$ \\
\hline
\end{tabular}

\section{Conclusion}

To step into Pharmaceutical market of developed nations, developing countries can use ACTD as a starting step. For having a quick access to the developed countries market, a single registration window is required which is achievable by harmonization of CTD and ACTD guidelines which is the need of the hour for the benefit of both the pharmaceutical industries and the regulatory authorities. The article shows a comparison of the CTD and ACTD format which can lay a basis for pharmaceutical industries of developing nations to enter the pharmaceutical market by understanding the advancement and clarity of the systems across the world for the drug product registration.

\section{References:}

1. Sulfanilamide Disaster.[Internet].[cited 2013 November]available from:

http://www.fda.gov/AboutFDA/WhatWeDo/Hi story/ProductRegulation/SulfanilamideDisaster/ default.htm.

2. Significant Dates in U.S. Food and Drug Law History.[Internet].[cited $2013 \quad$ November] available from:

http://www.fda.gov/aboutfda/whatwedo/history /milestones/ucm128305.htm.

3. The Thalidomide Tragedy: Another Example of Animal Research Misleading Science. [Internet] .[cited 2013 December] available from: 
http://www.pnc.com.au/ cafmr/online/research/ thalid2.html.

4. Chris J. B., Budiono S., I. Ralph Edwards; Drug Benefits and Risks: International Textbook of Clinical Pharmacology, Revised $2^{\text {nd }}$ edition; page no: 66.

5. Regulation of pharmaceuticals in the EU.[Internet].[cited 2013 November]available from: http://www.echamp.eu/regulation.html

6. José Luis Valverde ; Key Issues in Pharmaceuticals Law, page 358.

7. Recruitment at the European Medicines Agency.[Internet].[cited 2013 November] available from:

http://www.ema.europa.eu/docs/en_GB/docume nt_library/Other/2010/03/WC500075369.pdf
8. The ASEAN common technical dossier (ACTD) for the registration of pharmaceuticals for human use; September 2002.

9. Guidance for Industry M4Q: The CTD Quality; U.S. Department of Health and Human Services Food and Drug Administration Center for Drug Evaluation and Research (CDER)August 2001.

10. International conference on harmonization of Technical requirements for registration of Pharmaceuticals for human use ICH M2 EWG; ICH eCTD Specification V 3.2.2; 16-July-2008. 